Наталия Юрьевна Рассказова

\title{
ОБЩИЙ ПОДХОД К РЕГУЛИРОВАНИЮ ОБЕСПЕЧИТЕЛЬНЫХ ОТНОШЕНИЙ
}

1. Характерной чертой экономики последних десятилетий является расширение кредита и появление новых форм кредитования. Развитие кредита объективно требует развития обеспечительных инструментов. Подтверждением тому являются активные шаги, предпринимаемые Европейским Союзом для лучшего регулирования отдельных видов обеспечительных отношений. ${ }^{1}$ В рамках работы Евросоюза по гармонизации частного права создан документ под названием «Принципы, Определения и Модельные правила Европейского частного права. Проект общей справочной схемы (далее - DCFR)». Вместе с комментариями это произведение имеет весьма внушительный объем. ${ }^{2}$ Две больших раздела Модельных правил посвящены обеспечениям: раздел G книги IV «Личное обеспечительное обязательство» и книга IX «Реальные обеспечения, обременяющие движимое имущество».

Особенностью законодательства и доктрины в области обеспечительных отношений традиционно является недостаток внимания к общим положениям об обеспечениях. В классической литературе по цивилистике уделено достаточно внимания отдельным видам обеспечений, в основном поручительству и залогу, но теоретические положения об обеспечениях вообще практически не исследуются. Из отечественных монографий можно назвать только работу Б.М. Гонгало. ${ }^{3}$ Но ее большая часть посвящена анализу отдельных видов обеспечений, а в общетеоретической части нет ответа на многие вопросы, поставленных развитием обеспечительных отношений на рубеже веков. Относительно недавно на русский язык переведена работа X. Вебера ${ }^{4}$, в которой

1 См., например, Directive 2002/47/EC of 6 June 2002 on financial collateral arrangements // Official Journal of the European Communities 168. 27.6.2002. P. 43.

Principles, Definitions and Model Rules of European Private Law. Draft Common Frame of reference (DCFR). Full Edition.Prepared by the Study Group on a European Civil Code and the Research Group on EC Private Law (Acquis Group).Edited by Christian von Bar and Eric Clive.Volumes I-VI.Sellier.Munich, 2009.

3 Гонгало Б.М. Обеспечение исполнения обязательств. М., 1999.

4 Вебер Х. Обеспечение обязательств. М., 2009. 
автор, впрочем, не ставит задачу разработки общетеоретических положений. Статьи по теме также немногочисленны. ${ }^{5}$

Столь же лапидарны законодательные положения, регулирующие обеспечительные отношения в целом. В действующем Гражданском кодексе Российской Федерации (далее - ГК РФ) они сосредоточены в статье $329^{6}$ и явно недостаточны для ответа на многие вопросы, возникающие в практике использования обеспечений. В том числе, на главный вопрос: по каким критериям можно отнести к обеспечениям те многочисленные нестандартные инструменты, которые современный оборот пытается предложить кредиторам в качестве гарантий исполнения должниками обязательств. Между тем, выявление этих критериев необходимо, поскольку перечень обеспечений открыт (см. п. 1 ст. 329 ГК РФ). Иначе говоря, законодатель разрешает участникам оборота «придумывать» обеспечения, и при этом нередко связывает с наличием обеспечения специальные правовые последствия. ${ }^{7}$

Указав признаки, по которым тот или иной инструмент может быть отнесен к обеспечительным, необходимо выявить принципы, в соответствии с которыми надлежит регулировать права и обязанности вовлеченных в отношения лиц.

Обеспечение необходимо только на случай конкуренции прав кредитора с правами других лиц. Поэтому особенностью обеспечительных отношений является их сложная структура. В эти отношения включены: должник; кредитор, которому предоставлено обеспечение; другие кредиторы должника; лица, предоставившие обеспечение (обеспечительные должники), притом предоставившие обеспечения разных видов. Иначе говоря, обеспечение всегда поро-

5 См.: Белов В.А. Теоретические проблемы учения о способах обеспечения исполнения обязательств // Законы России: опыт, анализ, практика. 2006 г. N 6. Нигматулина Л.Б. Понятие и юридическая природа обеспечительного правоотношения. Юридический мир. 2001. Июль. Рассказова Н.Ю. к учению об обеспечении обязательств // Правоведение. 2004. № 4.

6 «Статья 329. Способы обеспечения исполнения обязательств

1. Исполнение обязательств может обеспечиваться неустойкой, залогом, удержанием имущества должника, поручительством, банковской гарантией, задатком и другими способами, предусмотренными законом или договором.

2. Недействительность соглашения об обеспечении исполнения обязательства не влечет недействительности этого обязательства (основного обязательства).

3. Недействительность основного обязательства влечет недействительность обеспечивающего его обязательства, если иное не установлено законом».

7 Например, ст. 102 ГК РФ: «...акционерное общество вправе выпускать облигации на сумму, не превышающую размер уставного капитала либо величину обеспечения, предоставленного обществу в этих целях третьими лицами, после полной оплаты уставного капитала»; ст. 384 ГК РФ: «...к новому кредитору переходят права, обеспечивающие исполнение обязательства...»; ст. 587 ГК РФ: «существенным условием договора, предусматривающего передачу под выплату ренты денежной суммы или иного движимого имущества, является условие, устанавливающее обязанность плательщика ренты предоставить обеспечение исполнения его обязательств...»; ст. 813 ГК РФ: «при невыполнении заемщиком предусмотренных договором займа обязанностей по обеспечению возврата суммы займа, а также при утрате обеспечения или ухудшении его условий по обстоятельствам, за которые займодавец не отвечает, займодавец вправе потребовать от заемщика досрочного возврата суммы займа и уплаты причитающихся процентов...». 
ждает правовую конструкцию, включающую несколько правоотношений и затрагивающую интересы более двух, а часто - много более двух, лиц. Но если так, то необходимо определить логику разрешения противоречий между интересами заинтересованных лиц.

Явно недостаточно регулирование отношений, возникающих после исполнения обеспеченного обязательства одним из обеспечительных должников. Правила, установленные для обеспечений отдельных видов недостаточны. Поскольку исполнение обязательства может одновременно обеспечиваться поручительством, залогом, и т. д., после реализации одного из обеспечений, возникают отношения, в которых участвуют должники, предоставившие обеспечения разных видов. Это с необходимостью предполагает наличие общих норм, применимых при любой комбинации обеспечений.

Поскольку отличительные признаки обеспечительных отношений имеют значение для квалификации трансграничных сделок и определения их последствий, поставленные вопросы требуют решения и на наднациональном уровне.

Перечисленные проблемы (а это лишь самые очевидные) позволяют уверенно утверждать, что выработка общего подхода к регулированию обеспечительных отношений является насущной задачей правовой науки и законодателя.

2. Представляется, что все разнообразные обеспечительные инструменты объединяет цель, ради которой они используются. В цивилистике вопрос о цели действий сторон разрешается с помощью понятия о материальном основании сделки и порожденного ею обязательства, то есть понятия о каузе.

Не ставя задачей специально исследовать вопрос о каузе, мы будем исходить из ее классического понимания. Вопрос о каузе - это вопрос о том, зачем лицо совершило сделку и вступило в обязательство (почему передало вещь, обещало уплатить деньги и т. д.), что оно хочет получить в качестве эквивалента за свое предоставление. кауза - та непосредственная правовая циель, которую преследует сторона, совершая сделку или вступая в обязательство. ${ }^{8}$

Какова же кауза обеспечительной сделки и возникающего из нее обеспечительного обязательства? Поскольку цель осознается и формулируется на основе интереса, логично начать с анализа того интереса, который руководит сторонами обеспечительного обязательства. Очевидно, этот интерес связан с созданием обеспечения, т. е. с желанием предоставить кредитору (получить 
от должника) дополнительную гарантию исполнения основного обязательства. Назовем этот особый интерес обеспечительным.

Именно он заставляет заинтересованных лиц создавать обеспечения. Он же формирует особое основание обеспечительных обязательств, особую каузу. Назовем ее по аналогии - обеспечительной.

По содержанию обеспечительная кауза существенно отличается от традиционно выделяемых causa donandi, causa credendi и causa solvendi. Должник в обеспечительном обязательстве обязывается не потому, что хочет соответственно одарить кредитора, получить что-либо от него или освободиться от долга перед ним. Он преследует особый - обеспечительный - интерес, и основанием его действий является цель удовлетворения именно этого интереса. Наличие особой каузы, лежащей в основе обеспечительных отношений, признавал А. С. Кривцов. Исследуя различные договоры с точки зрения их каузы, он включает в перечень pignus (залог), считая, что получение вещи в обеспечение является «достаточным эквивалентом за обязанность возвращения вещи... лежащую на... залоговом верителе. Что же касается до эквивалентной обязанности в пользу... залогодателя... то таковою является... отношение, которому закладное право составляет асcessorium». ${ }^{9}$

В чем же состоит правовая оригинальность обеспечительной каузы? В том, что она входит в corpus одной сделки (обеспечительной), но связана с обстоятельствами, относящимися к другим сделкам и обязательствам. Через нее эти обстоятельства влияют на обеспечительное обязательство. Так, основанием недействительности обеспечительного обязательства является недействительность основного (это положение указано в п. 3 ст. 329 ГК). Это дополнительное основание недействительности, понятно, не устраняет общих оснований (например, обязательство поручителя будет недействительно вследствие порока договора поручительства по субъектному составу и т. д.).

Рассмотрим пример. Стороны заключили договор поручительства в обеспечение возврата заемщиком суммы займа. кауза договора поручительства следует из его определения (ст. 361 ГК): поручитель обязуется платить кредитору потому, что он хочет обеспечить исполнение должником договора займа. В данной каузе воплощен обеспечительный интерес, о котором мы говорили выше. Этот интерес, а через него и кауза поручительства, связаны с договором займа. каким образом? Наличие долга заемщика включается в содержание каузы договора поручительства. Если окажется, что долга нет (например, не было факта передачи денег заемщику), у сторон пропадает обеспечитель- 
ный интерес. Отсутствие обеспечительного интереса порочит обеспечительную каузу договора поручительства. Поскольку кауза входит в corpus сделки как основания обязательства, ${ }^{10}$ ее порок влечет недействительность договора поручительства и обязательства поручителя.

Важно подчеркнуть, что связь между обеспечением (его каузой) и основным обязательством носит именно юридический характер. Гарантировать исполнение основного обязательства можно с помощью различных правовых инструментов. Между ними (обязательством и инструментом) всегда будет существовать фактическая связь (иначе откуда возникнет проблема гарантии исполнения?). Но из этого с необходимостью не следует наличия между ними и правовой связи. Так, выдача банковской гарантии (independent guaranty) всегда фактически связана с основным обязательством. Но в силу ст. 370 ГК РФ «Независимость банковской гарантии от основного обязательства» эта связь не имеет правового значения.

В ряде случаев обеспечительные обязательства возникают не на основании сделки, а в силу указанных в законе обстоятельств (п. 5 ст. 488, ст. 532, ст. 587 и др. ГК РФ). При этом законодатель исходит из предположения о наличии у сторон обязательства обеспечительного интереса. В этом случае наличие обеспечительной каузы следует из закона.

3. Обеспечительная кауза (обеспечительная цель) объясняет и механизм действия обеспечения. Основой этого механизма является признание служебной роли обеспечительных обязательств. Чему служит обеспечение? Оно создает для кредитора в основном обязательстве дополнительный, внешний по отношению к этому обязательству источник его исполнения. Если правовой инструмент создан с обеспечительной целью, он существует ради достижения этой цели. ко всем обеспечениям применимо сказанное И.А. Покровским по поводу залога: «Закладное право имеет служебный характер: оно должно лишь обеспечивать требование кредитора и потому является отношением добавочным к личному обязательственному отношению между кредитором и должником». ${ }^{11}$

Отпадение у лица обеспечительной цели должно означать для него прекращение обеспечения. Если из условий уступки прав по основному обязательству не следует, что к цессионарию перешли права по обеспечительному обязательству, это обязательство полагается прекращенным. ${ }^{12}$ Изначальное отсутствие в отношениях сторон обеспечительной цели означает, соответственно, что обеспечение не может считаться возникшим. Так, суд признал дого-

\footnotetext{
10 Гамбаров Ю. С. Курс гражданского права. Т. 1: Часть общая. СПб., 1911. С. 707.

11 Покровский И.А. Основные проблемы гражданского права. М., 1998. С. 218.

12 См. постановление Президиума Высшего Арбитражного Суда РФ от 6 марта 2002 г. N 7144/01.
} 
вор о залоге, заключенный обществом после уступки прав из основного обязательства, ничтожным. ${ }^{13}$

Из сказанного с необходимостью вытекает утверждение о том, что в основном и обеспечительном обязательствах кредитором должно являться одно и то же лицо. Иной подход создаст отношения, которые, даже при обнаружении их экономической целесообразности, нельзя квалифицировать как обеспечительные. По этой причине нельзя согласиться с предложением о допустимости изолированной уступки прав из основного обязательства с сохранением у цедента прав из обеспечительного обязательства. ${ }^{14}$

Подчеркнем, что сделанный вывод должен применяться как к акцессорным, так и к независимым обеспечениям. конечно, в отношении последних необходимо специальное обоснование их служебной роли. Акцессорное обеспечение в силу своей природы связано с правом из конкретного основного обязательства и при перемене лиц в этом обязательстве либо следуют за ним (это общее правило - ст. 384 ГК РФ), либо прекращается. Но как связать с правами из основного обязательства независимое от него обеспечение? Например, бенефициар по банковской гарантии уступил право требования из основного обязательства третьему лицу. Сохраняет ли он право требовать исполнения по гарантии? Ответ должен быть дан с учетом следующего обстоятельства. Независимость банковской гарантии проявляется в отношениях между бенефициаром и гарантом (на это прямо указывает ст. 370 ГК РФ). В отношениях же между бенефициаром и принципалом права бенефициара основаны на согласованной сторонами обеспечительной цели, ради достижения которой кредитору (бенефициару) предоставлены права из банковской гарантии. Соответственно, в этих отношениях (отношениях между принципалом и бенефициаром) право бенефициара заявить требование по гарантии оказывается зависимым от основного обязательства. Условия соглашения между принципалом и бенефициаром обязывают бенефициара перед принципалом надлежаще использовать свое право из гарантии, т.е. использовать его в обеспечительных целях. Поэтому требование бенефициара к гаранту, заявленное в противоречии с этой целью (то есть в отсутствии у бенефициар права требования к должнику), в отношениях между бенефициаром и принципалом должно рассматриваться как нарушение условий договора. Последствием такого нарушения явится обязанность должника уплатить не только долг по основному обязательству новому кредитору, но и сумму, уплаченную гарантом по требованию бенефициара, по-

13 См. постановление ФАС Северо-Западного округа от 2 июля 2001 г. N A26-4822/00-01-10/209.

14 Крашенинников Е.А. К вопросу об изолированной уступке права требования, обеспеченного поручительством // Очерки по торговому праву: сборник научных трудов. Выпуск 7, Ярославль, 2000. Критику этой позиции см.: Рассказова Н.Ю. Уступка требования, обеспеченного поручительством // Сборник статей к 55-летию Е.А. Крашенинникова. Ярославль, 2006. 
скольку платеж по банковской гарантии в любом случае осуществляется за его, принципала, счет. При таких обстоятельствах, принципалу должна быть предоставлена защита его интересов. В основе такой защиты, как видим, лежит идея о служебной роли любых обеспечительных обязательств. Вопрос о способах такой защиты требует отдельного рассмотрения, поскольку зависит от деталей регулирования отношений между бенефициаром и гарантом. конечно, стороны основного обязательства могут договориться о сохранении у бенефициара требования по гарантии и в случае уступки права из обеспеченного обязательства. Мотивы такого соглашения могут быть различны: уплата долга третьего лица, авансовый платеж по будущему обязательству и т. д. Очевидно, однако, что такое соглашение преобразует право требования, и оно утрачивает свою обеспечительную природу. Обеспечение не может существовать вне своей служебной по отношению к основному обязательству роли.

4. Почему так трудно понять право иного времени или другого народа, опираясь исключительно на текст закона? Очевидно, по той же причине, по которой трудно получить истинное представление о человеке по его фотографии. Дело в различиях между внешним и внутренним, формой и содержанием, строением и функцией. конечно, право ценно именно своей формальной стороной. Продуманная форма, лочически выверенная структура крупных и мелких элементов - необходимые черты права. Поэтому так велика в юристах любовь к стройности правовой системы, так силь'но стремление к «симметрии» правового материала (действительно - недействительно, нарушил - не нарушил, черное - белое, и tertium non datur). Но сугубо формальный подход к познанию права неплодотворен. Обратимся к яркой метафоре Рудольфа фон Иеринга: «Цель органов лежит в их функциях; органы существуют чтобы производить определенные отправления, с этой целью сообразуется и вся их организация. Насколько это имеет силу для физического организма, настолько и для организма права. И здесь только познание функций права приводит к пониманию его органов, физиология - к истинному пониманию анатомии». ${ }^{15}$

Сегодня, как и прежде, необходимо разграничивать формальный и функциональный подходы к познанию, формулированию и толкованию права. Первый с уверенностью можно назвать консервативным, второй характеризует более быстрое и гибкое приспособление правовой системы к потребностям оборота. Мы утверждаем, что при регулировании обеспечительных отношений функциональный подход сегодня является единственно приемлемым.

Начнем с очевидного: формы кредита рождаются из потребностей и возможностей оборота. А в последние десятилетия благодаря информационным технологиям оборот производит несравнимое с прошлым разнообразие кре- 
дита. Спутники кредита - обеспечительные обязательства. Разнообразие кредита с необходимостью требует разнообразия обеспечений. Признание за оборотом права творить новые формы заимствований требует признания за участниками оборота права создавать новые обеспечения. Но «творческая деятельность» оборота ориентирована отнюдь не на сохранение стройной системы правовых конструкций, а на правовые инструменты, хорошо выполняющие свои функции. Желание сохранить симметричной правовую картину мира подавляет оборот, не заботясь в каждом конкретном случае о том, насколько это оправдано. Готовность оценить функциональное значение правового инструмента предполагает не просто доверие к обороту, но признание свободы воли его участников основой нормального развития имущественных отношений.

Иллюстрацией к сказанному является отказ нашей практики признавать соглашения об удержании правового титула в качестве способа обеспечения исполнения обязательств. Суды рассматривали складывающиеся между сторонами отношения исключительно с точки зрения формы. Если у лица сохранилось право собственности - лицо обладает правомочиями собственника, которые могут быть ограничены только в установленном порядке. Соглашение же сторон об удержании титула собственности в обеспечительных целях, в зависимости от обстоятельств, признавалось либо недействительной сделкой (по общему правилу, прикрывающей договор о залоге), либо сделкой, смысл которой был далек от того, что имели ввиду стороны. Только в последнее время обеспечительное удержание титула начало признаваться у нас как правомерный самостоятельный способ обеспечения исполнения обязательств. ${ }^{16}$

К обеспечительным обязательствам применяются специальные правила, а кредитор, требования которого обеспечены, приобретает преимущества перед необеспеченными кредиторами. как при открытом перечне обеспечений определить, можно ли подчинять те или иные инструменты обеспечительному правовому режиму?

Рассмотрим пример. Банк готов предоставить Н. кредит под соразмерное обеспечение. Например, под поручительство М. Но М. не желает заключать договор поручительства, однако готов выступить в роли солидарного должника по кредитному договору, не претендуя при этом на получение части кредита. Изменим ситуацию. Н. и М. нуждаются в кредите. кредит предоставляется им как солидарным должникам. Одинаково ли положение М. в первом и втором случаях? С формальной точки зрения - да, одинаково. Но если учесть волю сторон, в первую очередь, самого М., то очевидно, что оно должно отличаться. Ведь правовое положение должника (обычного) и лица, предоставив- 
шего обеспечение за другого, различно. Эти различия отчетливо видны на стадии окончательных расчетов между должником и лицом, погасившим его долг.

Как определить, какие нормы применять к отношениям сторон, если один и тот же институт может иметь разные функции (как в приведенном примере институт солидарной ответственности), и наоборот, разные институты - одну функцию (например, акцессорные личные обеспечения, с одной стороны, и независимые, с другой)? Используемые в обороте обеспечительные конструкции нужно оценивать с точки зрения их функционального назначения. Такой подход опирается на основополагающий принцип гражданского права - принцип свободы воли участников оборота - и поэтому способен обеспечить эффективность правового регулирования. Используя метафору Иеринга, мы утверждаем: если организм нормально функционирует, недостатки его строения несущественны.

Функциональный подход обесчечивает целостность института обеспечительных обязательств и согласованность с нормами других институтов. Например, следуя функциональному подходу, необходимо исключить неустойку и задаток из числа обеспечений. Названные инструменты направлены на стимулирование должника к исполнению обязательства под страхом применения соответствующих санкций. Нормы же об обеспечениях в силу своей объективной природы должны не подталкивать должника к исполнению должником обязательства, а защищать кредитора от риска неисполнения. Поэтому действие обеспечительного механизма состоит не в применении санкций, а в использовании дополнительного источника, «резерва», за счет которого при неисправности должника будет исполнено основное обязательство. Неудивительно, что договорные условия о неустойке или задатке не рассматриваются на практике как условия о представлении должником обеспечения. Обеспеченным считается долг, уплата которого гарантирована залогом, поручительством, банковской гарантией.

5. Основой регулирования гражданских отношений является метод равенства сторон (ст. 2 ГК РФ). Этот метод обеспечивает такое юридическое положение, при котором участники оборота равно свободны в определении того, вступать ли им в договор и на каких условиях. Но формально - юридически находясь в равном положении, стороны могут быть не равны фактически, не равны в возможностях достижения своего интереса. Очевидно, в различном положении находятся защищенный опытом своих специалистов процветающий банк - займодавец и не разбирающийся в деталях кредитования мелкий заемщик; уклоняющийся от уплаты долга должник и доверившийся ему кредитор, вынужденный второпях искать средства для исполнения в срок собственных обязательств. Понятно, что законодатель не может удовлетворить все 
интересы, а потому его задача - создать справедливый баланс интересов. Для достижения такого баланса при конструировании и толковании правовых норм используется понятие о сильной и слабой сторонах в отношении. С помощью различных юридических приемов слабой стороне создаются условия, компенсирующие ее неравенство по отношению к фактически сильному контрагенту. Многовековой опыт регулирования частноправовых отношений предлагает богатый выбор таких приемов: предоставление права одностороннего изменения или прекращения правоотношения, права на получение информации, права на заявление дополнительных требований и т. д. Найти соответствующий правовой инструмент не составляет труда. Сложнее решить, какая сторона в отношении является слабой. кого должен поддержать законодатель в отношениях между двумя главными фигурами гражданского оборота - должником и кредитором? Ответ зависит от времени и места действия норм.

В 70-х годах 19 века Рудольф фон Иеринг писал: «...Симпатии к должнику являются признаком слабой эпохи. Сама она называет это гуманностью. Сильная эпоха заботится прежде всего о том, чтобы верителю было обеспечено его право, и не боится строгости по отношению к должнику, если она необходима для поддержания прочности оборота, доверия и кредита». ${ }^{17}$ Современные правопорядки в большинстве ориентированы на защиту кредитора. Тот же подход прослеживается в праве ЕС.

Традиционной для русского и советского права до недавнего времени считалась поддержка должника. Должник слаб уже потому, что обременен долгом - такое обоснование встречается в классических учебниках русского гражданского права. Описанный подход всегда питался идеологией православия. В социалистическом государстве, притом, что и кредитор, и должник в большинстве случаев «кормились» из одних рук - из рук государства, эта идея получила объективное экономическое основание: зачем правой рукой отбирать средства у нарушившего обязательство должника, если левой рукой его, так или иначе, придется поддерживать?

Постсоветский период развития отечественной правовой системы показал, что поддержка должника в ущерб кредитору, если так можно выразиться, «морально» устарела. Наше частное право постепенно переориентируется. ${ }^{18}$ При подготовке концепции развития гражданского законодательства ${ }^{19}$ идея за-

Иеринг Р. ф.. Борьба за право // Избранные труды. В 2 т. Т. 1. СПб, 2006. С. 76-77.

Этот процесс ярко отражен в эволюции законодательства РФ о банкротстве.

Концепция развития гражданского законодательства Российской Федерации, подготовленная Советом при Президенте Российской Федерации по кодификации и совершенствованию гражданского законодательства во исполнение Указа Президента Российской Федерации от 18 июля 2008 г. № 1108 «О совершенствовании Гражданского кодекса Российской Федерации» (одобрена решением Совета при Президенте РФ по кодификации и совершенствованию гражданского законодательства от 07.10.2009). Доступно в СПС «консультант». 
щиты кредитора нашла поддержку в рабочих группах. Экономическая основа такого подхода лежит на поверхности: оборот живет кредитом, а значит, готовностью кредитора кредитовать. Без веры кредитора в реальность уплаты долгов все останавливается. Поэтому защита интересов кредитора - необходимое средство для поддержания оборота. Но верно ли объяснять поддержку оборота именно слабостью кредитора? Разве законодатель, вводя соответствующее регулирование, не может руководствоваться другими соображениями, в частности сугубо утилитарными? конечно, может. Но в данном случае мы склонны видеть источником нового для нашего законодателя подхода экономические изменения, указавшие на объективную расстановку сил. Развитый оборот более рисковый для кредитора, т. к. выводит на рынок много потенциально несостоятельных должников, а потому кредитор утрачивает позицию сильной стороны в обязательстве. Этот тезис подтверждает положение ст. 401 ГК РФ о том, что неполучение средств от должника не освобождает кредитора, осуществляющего предпринимательскую деятельность, от ответственности перед его собственными кредиторами. А если речь идет о денежном обязательстве, то это положение на практике распространяется и на иных кредиторов, в частности граждан-потребителей. ${ }^{20}$ Очевидно, что проблема слабой стороны выходит на пределы одного правоотношения. кредитор не просто слабая сторона, он есть слабое звено в цепи договорных отношений. Затруднения одного кредитора в получении исполнения от должника могут вызвать проблемы у многих связанных с ним лиц. Сегодня для установления справедливого баланса интересов требуется защита кредитора.

Иллюстрацией этого вывода является дискуссия по поводу влияния смерти должника на судьбу поручительства. Продебиторский подход предполагает, что интерес поручителя нарушается, если место должника заступают его наследники, а потому смерть должника должна влечь прекращение поручительства. ${ }^{21}$ Прокредиторский подход - наоборот, требует признать приоритет интересов кредитора, а потому сохранить поручительство при смерти должника. ${ }^{22}$ Интересно, что во внесенном в Государственную Думу Проекте изменений ГК РФ вопрос о судьбе поручительства не затронут. ${ }^{23}$ Это указывает на накал борьбы продебиторского и прокредиторского подходов. Во главе борющихся сил оказались, соответственно, Верховный и Высший Арбитражный Суды РФ.

20 См.: Витрянский В.В. Договор займа: общие положения и отдельные виды договора. М., 2004. С. 232.

21 См. проект федерального закона № 337108-5 «О внесении изменений в статью 367 части первой Гражданского кодекса Российской Федерации». Проект не был одобрен Советом при Президенте Российской Федерации по кодификации и совершенствованию гражданского законодательства.

22 Пункт 1.3 подразд. 3 разд. V «Законодательство об обязательствах (Общие положения)» концепции развития гражданского законодательства Российской Федерации.

23 См. п. 177 статьи 1 проекта Федерального закона N 47538-6 «О внесении изменений в части первую, вторую, третью и четвертую Гражданского кодекса Российской Федерации, а также в отдельные законодательные акты Российской Федерации». Доступно в СПС «консультант». 
Пленум Верховного Суда в акте официального толкования ст. 367 ГК РФ указал, что «поручитель наследодателя становится поручителем наследника лишь в случае, если поручителем было дано согласие отвечать за неисполнение обязательств наследниками». ${ }^{24}$ Пленум же ВАС РФ дает прямо противоположное официальное толкование: «Смерть должника не прекращает поручительство..., положения пункта 2 статьи 367 ГК РФ применению не подлежат; иное может быть предусмотрено договором поручительства». ${ }^{25}$ На что указывает столь радикальное противоречие? Поскольку Верховный Суд РФ рассматривает споры с участием граждан-потребителей, его позиция выражает квалифицированное мнение о реальном положении дел в современной России: низкий уровень доходов граждан помноженный на низкую правовую культуру на фоне доступности кредита и его агрессивного навязывания гражданам. Но такое не радостное положение не отменяет логику рынка, то есть необходимость поддержки кредитора. И именно на этой логике основана позиция Высшего Арбитражного Суда РФ, рассматривающего споры с участием граждан-предпринимателей и юридических лиц. Отказываться от этой логики нельзя. Но, может быть, для граждан-потребителей следует сделать исключение.

В обеспечительных отношениях, часто усложненных участием нескольких лиц, которые, кстати, могут последовательно находиться в роли то должника то кредитора, вопрос о поиске баланса интересов приобретает особое значение. ${ }^{26}$

Так, позиция кредитора в основном обязательстве, на первый взгляд, представляется сильной уже потому, что он обладает обеспеченным правом. В результате у такого кредитора не одно, как у обычного, а два требования (из основного обязательства и из обеспечительного). Но удвоение требования само по себе не означает усиления позиции кредитора. Сила правовой позиции кредитора зависит не от количества, а от качества требований. качество же требования - это его действительность (качество в материально-правовом смысле) и реализуемость (качество в процедурно-правовом смысле). Обратимся к истории новейшего российского законодательства об ипотеке. Еще несколько лет назад кредиторы (в первую очередь, банки), несмотря на наличие тщательно составленных договоров о залоге и сохранность предметов залога, утверждали, что залог не работает, поскольку права залогодержателя, пра-

24 Пункт 62 постановления Пленума Верховного Суда РФ от 29.05.2012 N 9 «О судебной практике по делам о наследовании».

25 Пункт 20 постановления Пленума Высшего Арбитражного Суда РФ от 12 июля 2012 г. N 42 «О некоторых вопросах разрешения споров, связанных с поручительством»

26 Примечательно, что Р. ф. Иеринг иллюстрирует идею о необходимости поддерживать кредитора (ссылка на эту идею сделана выше) примерами из законодательства Юстиниана, добрая половина которых касается именно обеспечений: субсидиарной ответственности поручителя, отсрочки реализации предмета залога и т. д. (Иеринг Р. ф. УК. соч. С. 76. Сноска 24). 
ктически, не реализуемы: обратить взыскание на предмет залога можно было (за редкими исключениями) только в судебном порядке, т. е. в результате долгой и дорогой процедуры; заложенное жилье было невозможно освободить от проживающих в нем залогодателя и членов его семьи, а, значит, наиболее распространенный предмет ипотеки оказывался неликвидным. Законодательство было ориентировано на защиту залогодателя, а когда речь шла о залогодателепотребителе - исключительно на его защиту. Следствием этого явилось не просто удорожание кредита, но сворачивание ипотечного кредитования в целом. Защита законодателем интересов должника обернулась затруднениями в реализации его же (должника) интереса в получении кредита.

Итак, сам факт обеспечения исполнения обязательства не делает кредитора более сильной стороной в обязательстве. Поэтому кредитору с обеспечением должна быть предоставлена защита как любому другому кредитору.

В случае предоставления обеспечения третьим лицом, это лицо, будучи сначала обязанным, по исполнении обеспечительного обязательства получает регрессное или суброгационное требование к должнику, т. е. становится кредитором. В этом случае его интерес должен защищаться в общем порядке, за одним исключением. Исключение касается конфликта интересов первоначального кредитора и ставшего кредитором обеспечительного должника. В случае суброгации конфликт разрешается на основе принципа nemo censetur subrogare contra se («никто не допускает вступления в свои права против своих интересов»). ${ }^{27}$ Например, при частичной уплате долга поручитель приобретает в порядке суброгации часть требования к должнику. В результате на стороне кредитора в основном обязательстве оказываются два лица. Поскольку речь идет об обеспечительных отношениях, изначальная цель которых - защитить интерес кредитора в основном обязательстве, интерес этого кредитора должен иметь приоритет перед интересом лиц, предоставивших обеспечение, даже если эти лица также станут кредиторами должника. Это положение актуально при недостаточности у должника средств для удовлетворения требований всех кредиторов. Следует предположить, что аналогичный подход должен иметь место и при конкуренции интересов первоначального кредитора и обеспечительного должника, получившего в отношении основного должника регрессное требование.

6. Со стороны деловых кругов все чаще слышатся упреки российскому законодателю: частные отношения зарегулированы, стороны не имеют возможности реализовать свои интересы, будучи стеснены обилием императивных

27 На этот принцип ссылаются и классики цивилистики (например, см.: Морандьер Л.Ж. Гражданское право Франции: Т. 2. М., 1960. С. 557), и комментаторы Principles of European Law. V. 4. Personal Security (PEL/ Drobnig, Pers. Sec. C. 305). 
требований закона и судебной практикой, сопротивляющейся признанию соглашений, непоименованных в российских законах, но признанных в мировой практике. Это приводит к выводу отношений под действие иных юрисдикций, и, опосредованно, к бегству капитала. Безусловно, в законодательстве об обеспечениях немало ограничений, от которых в современных условиях можно отказаться. Безусловно, суды весьма осторожны в признании незнакомых обеспечительных конструкций. Безусловно, обеспечительные отношения как гражданско-правовые должны строиться на началах свободы и диспозитивности. Но реализовывать эти начала необходимо с учетом двух обстоятельств. Первое имеет формально-юридический характер, второе - сугубо практический.

С формально юридической точки зрения, гражданское право всегда включало, помимо частноправовых, публично правовые нормы. ${ }^{28}$ Эти нормы ограничивают автономию участников гражданских отношений в общезначимых целях. Ограничения вводятся либо путем императивных законодательных установлений, в том числе запретов, либо путем стимулирования определенного поведения под страхом утраты правовой защиты. Например, российский законодатель императивно ограничил виды независимых обеспечительных обязательств теми, которые прямо предусмотрены законом, т. е. запретил участникам оборота создавать независимые обеспечения на основе частных соглашений (ст. 329 ГК РФ). Примером стимулирующего регулирования является установление двухлетнего пресекательного срока для реализации требования кредитора к поручителю в том случае, если стороны не предусмотрели иной срок в договоре поручительства (ст. 367 ГК РФ).

Обеспечительные отношения имеют публичное значение уже потому, что затрагивают интересы не только их непосредственных участников. Это не удивительно, поскольку обеспечение предоставляется кредитору, чтобы установить для него привилегированное положение на случай конкуренции его прав с правами третьих лиц. Но где публичность - там ограничение диспозитивности.

С практической точки зрения ограничение диспозитивности может быть оправдано фактическим уровнем правопорядка и правосознания. В частности, впервые введя в практику независимое обеспечительное обязательство - банковскую гарантию - законодатель не только запретил участникам оборота создавать подобные обеспечительные инструменты, но и ограничил кругом профессиональных финансовых институтов - банков и страховых компаний - число лиц, наделенных правом выдавать гарантии. Осторожный подход 
был оправдан. Это подтвердили многочисленные поначалу ошибки в применении норм о банковской гарантии, связанные с непониманием природы нового для нашей экономики вида обеспечений. Сегодня запрет может быть, если не отменен, то смягчен. Например, накопленный опыт позволяет расширить круг субъектов, имеющих право обязаться по независимому обеспечительному обязательству. Но стоит ли допускать полную свободу в установлении обеспечений подобного рода - вопрос политики права, решать который нужно на основе анализа эмпирически подтвержденных потребностей и возможностей оборота, а не на основе отвлеченных рассуждений. В частности, проектом изменений ГК РФ предложено включить в ст. 368 ГК РФ положение о том, что независимые гарантии могут выдаваться коммерческими организациями. ${ }^{29}$

Необходимо подчеркнуть, что обсуждение преимуществ диспозитивности над императивностью в регулировании гражданских отношений не имеет отношения к вопросу о преимуществах правовых систем, основанных на common law. Даже если принять как аксиому, что в этих системах субъекты гражданского права, испытывая меньшее давление со стороны законодателя, имеют 'большую свободу, из этого отнюдь не следует, что страны common law дают образец «лучшего права». Соглашаясь с необходимостью устранять «зарегулированность» гражданских отношений, мы не готовы искать ей замену в принципах, на которых построено, в частности, англо-американское право. Опрометчиво уподоблять правовую систему магазину, на полках которого имеется широкий выбор вещей, а их качество гарантировано. Любая норма включена в систему правил, а ее наблюдаемый эффект определяется логикой системы. И не только формально- структурной, но и идеологической логикой. Готовы ли сторонники предпринимательской свободы принять и ее идеологическую основу, сформулированную, в частности, в работах создателя теории law and economics Ричарда Познера: экономическая эффективность - адекватная замена справедливости ${ }^{30}$ Взаимопроникновение правовых культур неизбежно. Но искусственное форсирование этого процесса опасно.

29 См. п. 177 статьи 1 проекта Федерального закона N 47538-6 «О внесении изменений в части первую, вторую, третью и четвертую Гражданского кодекса Российской Федерации, а также в отдельные законодательные акты Российской Федерации». Доступно в СПС «консультант».

30 Формулировку идеи Познера см.: Бетелл Т. Собственность и процветание. М., 2008. С. 26. Для более подробного знакомства с конфликтом, порожденным рекламой правовых идей common law, см. ответ Асcоциации друзей французской правовой культуры им. Анри Капитана на серию докладов Doing Business, сделанных в середине первого десятилетия нового века под эгидой Всемирного Банка: Цивилистические правовые традиции под вопросом (по поводу докладов Doing Business Всемирного Банка). М., 2007. 


\section{THE GENERAL APPROACH TO THE REGULATION OF SECURITY RELATIONS}

This article deals with the problem of the security rights regulation. This subject needs more attention from academics and lawmakers. Security cauza is considered as a main feature of security legal relationships. This implies the conclusion that a secured creditor and a securing creditor should be the same person. To provide for integrity of the security obligations institute, functional approach is treated as a preferable one (which is opposed to the formal approach). A secured creditor should be protected like any other creditor, because existence of the security itself does not place him in a stronger position. A balance between mandatory and dispositive regulation can only be found when the "time and place" of application of the law are taken into account.

Key words:

Security rights, collateral, principles for private law regulation. 